\title{
CIBERSOCIALIDADE, SOCIEDADE EM REDE E EDUCAÇÃO: SOBRE MOBILIZAÇÕES ESTUDANTIS EM TEMPOS DE REDES SOCIAIS
}

\author{
Juliana Brandão Machado ${ }^{1}$
}

\begin{abstract}
Resumo: O objetivo do texto é discutir as práticas de mobilização estudantil em tempos de virtualização das relações, a partir das suas manifestações nas redes sociais. Para tal discussão foram elencados os conceitos de sociedade em rede, cibersocialidade e juventudes. A motivação inicial parte do contexto de ocupação de um campus universitário por estudantes, em um cenário de mobilização e resistência que se expande nas redes sociais. A análise aponta que as manifestações estudantis, vividas na cibercultura, denotam novas práticas de democracia e, por conseguinte, instituem um novo processo pedagógico. A reconstrução dos princípios democráticos no contexto da sociedade em rede é a expressão de tais mobilizações. Portanto, as mobilizações estudantis nas redes sociais apontam outros sentidos para a vivência democrática, instauram relações sociais, rompem as fronteiras do "aqui e agora", e ensinam sobre política e educação.
\end{abstract}

Palavras-chave: Educação. Redes Sociais. Cibersocialidade. Mobilização Estudantil. Sociedade em Rede.

1 Doutora em Educação (UFRGS). Professora Adjunta da Universidade Federal do Pampa. E-mail: julianamachado@unipampa.edu.br. 


\section{INTRODUÇÃO}

Só podemos ser úteis socialmente se tomarmos certa distância e tratarmos de entender, antes de ter uma posição. (CASTELLS, 2014, p.168)

A análise de fenômenos contemporâneos requer cuidados do ponto de vista da produção de afirmações a seu respeito. Considera-se que certo distanciamento é sempre necessário para pensar os entendimentos mais profundos acerca daquilo que se processa. Ao se produzir um contexto novo, é fundamental uma reflexão crítica com vistas à buscara sua compreensão, tal qual a afirmação acima de Manuel Castells. É diante deste cenário que o texto é produzido: a vivência próxima e recorrente das manifestações estudantis, em defesa da Educação Pública. Tal proximidade motivou uma escrita reflexiva e a partir dela, fazendo uso de conceitos problematizados em minha trajetória de pesquisa, proponho discuti-la neste artigo (MACHADO, 2006; 2013).

A partir do contexto institucional vivido atualmente - a ocupação do campus Jaguarão da Universidade Federal do Pampa por estudantes de graduação, que formaram um coletivo intitulado "Bloco de Lutas pela Educação Pública” - para refletir sobre mobilização e resistência na universidade, expressivo da contemporaneidade: a articulação dos movimentos sociais na sociedade em rede. Sob o prisma desse cenário, serão explorados dois conceitos centrais: a sociedade em rede, na discussão de Castells (2007) e a cibersocialidade, a partir de Lemos (2008). Ressalto que não se trata de analisar o movimento em si, mas apenas tomá-lo como referente de motivação para a discussão. O objetivo deste texto é discutir as práticas de mobilização estudantil em tempos de virtualização das relações, a partir das redes sociais. Assim, o texto trará discussão conceitual da sociedade em rede e da cibersocialidade, articulados ao conceito de juventudes, seguido da análise do cenário da problematização e sua apresentação na rede social Facebook, com a busca pela articulação dos conceitos discutidos às manifestações estudantis. Por último, teço algumas conclusões, apontando as interconexões da temática com o campo educacional. 


\section{SOBRE JUVENTUDES, SOCIEDADE EM REDE E CIBERSOCIALIDADE ${ }^{2}$}

Na sociedade contemporânea, com o advento das Tecnologias da Informação e Comunicação (TIC), observamos um novo padrão de tempo sendo instaurado e, com ele, uma nova compreensão do espaço é apresentada. Castells, ao discutir a sociedade em rede, dedica um capítulo para cada um destes conceitos. Centraliza a "primazia do espaço pelo tempo, uma vez que, em sua concepção, o espaço organiza o tempo na sociedade em rede" (2007, p. 467). Inicialmente, faz-se necessário conceituar, nas palavras do próprio autor, a sociedade em rede que, curiosamente, Castells o faz na conclusão do livro, após apresentar seu pensamento analítico das configurações da sociedade em rede sob diversos aspectos:

Rede é um conjunto de nós interconectados. Nó é o ponto no qual uma curva se entrecorta. Concretamente, o que um nó é depende do tipo de redes concretas de que falamos. [...] Redes são estruturas abertas capazes de expandir de forma ilimitada, integrando novos nós desde que consigam comunicar-se dentro da rede, ou seja, desde que compartilhem os mesmos códigos de comunicação [...] Uma estrutura social com base em redes é um sistema aberto altamente dinâmico suscetível de inovação sem ameaças ao seu equilíbrio. (CASTELLS, 2007, p. 566)

Ao admitir que os conceitos de tempo e espaço estão sendo transformados pelo paradigma da informação e comunicação, sem com isso cair em um determinismo tecnológico, Castells amplia suas definições e instaura as ideias de espaço de fluxos e tempo intemporal. Para este autor, o espaço é a expressão da sociedade. Diante de uma nova configuração social, de uma nova estruturação do capitalismo atual em relação à sua organização, observa-se que a globalização instituiu processos de produção em nível mundial que perdem referências locais com a cultura e o espaço de produção. Na era da flexibilização do capital, surgem espaços que são construídos para comporem realidades globalizadas, que não instauram permanências de sujeitos, mas passagens - este é o espaço de fluxos:

O espaço de fluxos é a organização material das práticas sociais de tempo compartilhado que funcionam por meio de fluxos. Por fluxos entendo as

2 Essa seção retoma conceitos e discussões apresentados em Machado (2006) e Machado (2013). 
sequências intencionais, repetitivas e programáveis de intercâmbio e interação entre posições fisicamente desarticuladas, mantidas por atores sociais nas estruturas econômica, política e simbólica da sociedade. (CASTELLS, 2007, p. 501)

O espaço local, peculiar e particular ao sujeito, constitui o espaço de lugares: "um lugar é um local cuja forma, função e significação são independentes dentro das fronteiras da contiguidade física" (CASTELLS, 2007, p. 512). O autor não substitui o espaço de lugar pelo espaço de fluxos. A coexistência do espaço de fluxos e espaço de lugares remete à ideia de que o espaço tem suas representações distintas diante daquilo que se quer demarcar:

Portanto, as pessoas ainda vivem em lugares. Mas, como a função e o poder em nossas sociedades estão organizados no espaço de fluxos, a dominação estrutural de sua lógica altera de forma fundamental o significado e a dinâmica dos lugares. (CASTELLS, 2007, p. 517)

Pensando neste espaço local, singular da vida dos sujeitos, em que as experiências cotidianas se constroem, onde se vive e é regulado pelo tempo, na concepção de Elias (1998), a cidade se apresenta como um elemento fundamental. Henri Lefebvre (2001) discute a questão do urbano, significativa para o estudo das relações entre tempo e espaço. Realizando uma análise marxista do processo de industrialização e urbanização, o autor anuncia que a cidade existe antes do advento industrial, mas é a partir da industrialização que o sentido de urbanidade se configura. Em suas palavras, "o urbano contém o sentido da produção industrial" (LEFEBVRE, 2001, p. 81). O autor enfatiza a dicotomia entre o valor de uso da cidade em si, na vivência urbana, e o valor de troca dos bens de consumo que invadem a cidade. Uma das definições propostas por Lefebvre sobre a cidade apresenta-a como sendo uma "projeção da sociedade sobre um local" (2001, p. 56), e que ela constitui "o conjunto das diferenças entre as cidades" (2001, p. 57), salientando seu caráter de multiplicidade, e da constituição de um espaço de lutas entre grupos sociais com objetivos diferentes.

Santos (2008), ao analisar a "natureza do espaço", também se dedicou a discutir a questão do lugar e do cotidiano. Na sua concepção, o lugar é o intermédio entre o mundo e o indivíduo:

Cada lugar é, a sua maneira, o mundo [...] todos os lugares são virtualmente mundiais. Mas, também, cada lugar, irrecusavelmente imerso na comunhão com o mundo, torna-se exponencialmente diferente dos demais. A uma maior 
globalidade, corresponde uma maior individualidade. (SANTOS, 2008, p. 314)

O lugar cria a socialidade e, apoiado em Schütz, Santos ressalta o valor da proximidade entre as pessoas para o desenvolvimento dessa socialidade. Proximidade aqui não é compreendida simplesmente como diminuição de distâncias (o que incorpora a ideia da proximidade virtual), mas "a contiguidade física entre pessoas numa mesma extensão [...] vivendo com intensidade suas inter-relações" (Santos, 2008, p. 318).

Em relação à concepção de tempo, Castells aponta que "a modernidade pode ser concebida como o domínio do tempo cronológico sobre o espaço e a sociedade" (2007, p. 525). Na mesma linha de argumentação de Thompson (1991), o autor vai mostrando como o capitalismo instaura novas relações temporais ao mundo do trabalho, ou como o capital monetiza o tempo. Porém, sua argumentação articula-se no sentido de mostrar que o tempo linear e mensurável da sociedade moderna está sendo fragmentado na sociedade em rede, a ponto de o autor propor um tempo intemporal, conceito que remete ao espaço de fluxos. Esta é uma nova temporalidade, como menciona o autor, que coexiste com a noção de tempo cronológico, por ainda haver a existência de espaço de lugares na sociedade em rede (Castells, 2007, p. 527).

Assumindo as proposições de Elias (1998), a respeito do tempo como um construto social, e das noções de espaço de fluxos e espaço de lugares, de acordo com Castells, requer discutir a ideia de cibercultura. O conceito, de reconhecida complexidade teórica, tem no autor Pierre Lévy uma referência fundamental. Inicialmente, Lévy indica que a cibercultura é uma "nova forma de cultura" (Prefácio de LEMOS, 2008, p. 11). A especificidade dessa cultura caracteriza-se pela emergência da sociedade em rede e, com isso, das relações com as tecnologias da informação e comunicação.

O objetivo de destacar o conceito de cibercultura é o de apresentar algumas ideias pertinentes à inter-relação com o conceito de cibersocialidade. Uma discussão fundamental, proposta por André Lemos (2008), é a ideia de que para compreendermos a cibercultura é necessário compreender o fenômeno técnico no desenvolvimento da sociedade e da mediatização entre razão e técnica em diversos períodos históricos. Nessa abordagem, o autor situa as diferenças entre técnica e tecnologia desde a concepção grega até a contemporaneidade, enfatizando, sobretudo, a emergência da razão aliada à técnica na modernidade. Segundo o autor, esse é o pano de fundo para a criação da ideia de cibercultura:

O paradigma eletricidade/petróleo, motor elétrico e química de síntese no fim do 
século XIX muda, depois da Segunda Guerra Mundial, para um novo paradigma: energia nuclear, informática, engenharia genética. Este novo sistema técnico vai afetar a vida quotidiana de forma radical com a formação e planetarização da sociedade de consumo e do espetáculo. Este é o pano de fundo para o surgimento da cibercultura. (LEMOS, 2008, p. 51-2)

Para além do fenômeno técnico, a cibercultura vai instaurar-se como um processo que se inter-relaciona diretamente com a vida social: "A cultura contemporânea, associada às tecnologias digitais (ciberespaço, simulação, tempo real, processos de virtualização, etc.), vai criando uma nova relação entre a técnica e a vida social que chamaremos de cibercultura" (LEMOS, 2008, p. 15).

Uma nova relação com o tempo e o espaço é definida na cibercultura. A ideia, já apresentada anteriormente por Castells, de uma nova perspectiva de compreensão do tempo e do espaço, também é defendida por Lemos. A linearidade do tempo cronológico e a espacialidade do lugar se reestruturam e uma nova conceitualização de tempo e espaço, que é promovida através do

[...] surgimento da tecnologia digital, permitindo escapar do tempo linear e do espaço geográfico. Entram em jogo a telepresença, os mundos virtuais, o tempo instantâneo, a abolição do espaço físico, em suma, todos os poderes de transcendência e de controle simbólico do espaço e do tempo. (LEMOS, 2008, p.

Com as tecnologias digitais podemos observar a emergência do instantâneo, da simultaneidade e a possibilidade de contato entre pessoas para além da presença física. $O$ aqui e agora incorpora uma nova definição, já que, por exemplo, duas pessoas em pontos diferentes do planeta podem estar em uma teleconferência em locais e tempos distintos, comunicando-se e interagindo. Essa distinção faz parte das características da pós-modernidade, que modifica as concepções modernas de espaço e tempo:

Na modernidade, o tempo é um modo de esculpir o espaço, já que o progresso, a encarnação do tempo linear, implica a conquista do espaço físico. $\mathrm{Na}$ pósmodernidade, o sentimento é de compressão do espaço e do tempo, onde o tempo real (imediato) e as redes telemáticas, desterritorializam (desespacializam) a cultura, tendo um forte impacto nas estruturas econômicas, sociais, políticas e culturais. O tempo é, assim, um modo de aniquilar o espaço. Este é o ambiente comunicacional da cibercultura. (LEMOS, 2008, p. 67)

Outra ideia fundamental para a compreensão da cibercultura é a de 
ciberespaço. O ciberespaço, onde se processam as interações e a dinâmica considerada pelas tecnologias é, nas palavras de Lévy, "o novo meio de comunicação que surge da interconexão mundial dos computadores" (2007, p. 5). É o desenvolvimento do ciberespaço que possibilita a cibercultura, considerada como "o conjunto de técnicas (materiais e intelectuais), de práticas, de atitudes, de modos de pensamento e de valores que se desenvolvem juntamente com o crescimento do ciberespaço" (Idem).

$\mathrm{Na}$ esteira do desenvolvimento do ciberespaço, uma nova forma de relação entre as pessoas se desenvolve. É o que Lemos chama de cibersocialidade, que incorpora a socialidade contemporânea e a relação com o fenômeno tecnológico: "[...] a cibersocialidade é a sinergia entre a socialidade contemporânea e as novas tecnologias do ciberespaço" (LEMOS, 2008, p. 81).

A ideia de socialidade, defendida por Lemos (e ancorada em Maffesolli), se opõe ao conceito de sociabilidade, remetendo à emergência das relações sociais vividas num cotidiano do presente:

A socialidade marcaria os agrupamentos urbanos contemporâneos, diferenciando-se da sociabilidade ao colocar ênfase na tragédia do presente, no instante vivido além de projeções futuristas ou morais, nas relações banais do quotidiano, nos momentos não institucionais, racionais ou finalistas de toda a vida. (LEMOS, 2008, p.82)

Dessa forma, as ideias de socialidade, e cibersocialidade estão relacionadas à vivência de um cotidiano presentificado, àquilo que é vivido no aqui e agora das relações. Esse é o ponto em que observamos a relação entre a cibercultura e a sociedade em rede com os movimentos estudantis nas redes sociais. A cibersocialidade instaura e presentifica as relações sociais mediadas pelas tecnologias digitais, ou estabelecidas na rede social, desdobrando uma nova forma de cultura e convivência no cotidiano dos sujeitos.

A cibercultura também apresenta uma nova relação com o saber e a aprendizagem. A emergência do ciberespaço, segundo Lévy (2007), possibilita o desenvolvimento de novas formas de acesso à informação e novos estilos de raciocínio e conhecimento. A ideia de que as informações estão ao alcance de todos, mas que o "todo" não é alcançável, aliada às metáforas do surfe e da navegação, indicam que os saberes também são redefinidos na cibercultura. A singularidade das experiências e a simulação são características dessa dimensão: "o ciberespaço, suas comunidades virtuais, suas reservas de imagens, suas simulações interativas, sua irresistível proliferação de textos e de signos, será o 
mediador essencial da inteligência coletiva da humanidade" (LÉVY, 2007, p.167). Assim, problematizar a expansão das mobilizações estudantes na sociedade em rede, alicerçando a construção da cibersocialidade, implica reconhecer seu processo educativo, produtor de saberes em diferentes dimensões.

Para completar o quadro conceitual estabelecido, apresento a compreensão do conceito de juventudes, fundamental no contexto que está sendo discutido aqui. Ele é tomado na perspectiva de Abramo (1994) em sua dimensão histórica e sociológica e como um "problema da modernidade".

Abramo (1994) traz elementos significativos para pensarmos a questão das juventudes. Tanto do ponto de vista histórico quanto da caracterização das juventudes, a autora contribui para a análise desse fenômeno no campo sociológico. Ao retomar o desenvolvimento da análise sobre as juventudes em relação ao estabelecimento de uma cultura juvenil, cita o período do pós-guerra como instaurador de uma nova condição juvenil, relacionada à valorização do tempo livre e ao lazer e à aquisição de direitos sociais, como a extensão da escolarização obrigatória. Dessa forma, a etapa entre a infância e a vida adulta ganha visibilidade:

De modo geral, historiadores e sociólogos concordam em apontar as mudanças ocorridas no pós-guerra - principalmente aquelas vinculadas ao novo ciclo de desenvolvimento industrial e às medidas sociais do welfarestate -, como os fatores que criaram as condições para a configuração de uma nova condição juvenil. (ABRAMO, 1994, p. 28)

Por conta dessa visibilidade, afirma a autora, a condição juvenil começa a ser a condição estudantil, principalmente no Brasil, em que os jovens começam a ser percebidos, por volta da década de 1970, como agentes de mudança social. A atuação dos movimentos estudantis expressa a mobilização juvenil na época da ditadura militar brasileira.

Em outra obra, Abramo (1997) salienta que a visibilidade da condição juvenil aparece um tanto "desfocada" em nossa sociedade. Segundo a autora, a tematização sobre a juventude no Brasil não tem considerado os jovens como sujeitos, principalmente por estar diante da premissa da juventude como problema social e de considerar os jovens como sujeitos incapazes de atuarem nas proposições referentes ao segmento juvenil. Como destaca Abramo, ainda persiste a tematização social da juventude no Brasil amparada na sociologia funcionalista, que considera a juventude em relação ao processo de socialização vivido e suas disfunções. Peralva (1997) também recorre à discussão da 
Sociologia da Juventude como "Sociologia do desvio", indicando que jovem é aquele que se integra mal e que resiste ao processo de socialização, sendo o comportamento desviante inerente à experiência juvenil. Mais uma vez, encontra-se a dimensão da negatividade - o "não ser", ou "não estar apto a" - e a questão do jovem como problema social na caracterização da juventude: "a juventude só está presente para o pensamento e para a ação social como problema" (ABRAMO, 1997, p. 29).

Assumo aqui, em complementaridade à discussão estabelecida acima, e reafirmando a importância de uma concepção de juventudes positiva e propositiva, a definição proposta por Dayrell (2003, p. 42):

[...] entendemos a juventude como parte de um processo mais amplo de constituição de sujeitos, mas que tem especificidades que marcam a vida de cada um. A juventude constitui um momento determinado, mas não se reduz a uma passagem; ela assume uma importância em si mesma.

Ao destacar o conceito de juventudes pretendo enfatizar a compreensão desse grupo social como um segmento da população, com características específicas, levando em conta a pluralidade de experiências dessa etapa da vida. Na procura por ultrapassar a ideia das juventudes como uma transição ou um problema, dotados de negatividade, busco caracterizá-la em sua constituição plural, em que os aspectos de gênero, raça e etnia, classe social, religiosidade estejam presentes e, assim, componham sua definição. Por isso, falo em juventudes, reconhecendo-as em sua dimensão de complexidade, que é própria do humano.

Assim, a discussão que inicia na caracterização da sociedade em rede, propondo um aprofundamento das discussões sobre os conceitos de espaço e tempo, avançando pela complexidade da cibercultura e alterando as relações sociais, a partir da cibersocialidade, indicam uma possibilidade de conceber as juventudes, na contemporaneidade, imbricadas e produtoras desta sociedade em rede. Operar, no campo conceitual, com a ideia de juventudes, no plural, implica diretamente reconhecer o seu protagonismo na sociedade em rede. Para além da já discutida relação dos "nativos digitais" na contemporaneidade, a sua forma de relação com as tecnologias digitais, afirmo aqui a relevância da construção das mobilizações estudantis nas redes sociais, permeadas pelos conceitos já discutidos. Dessa maneira, pretendo explorar, na seção seguinte, alguns aspectos característicos destes movimentos. 


\section{AS MOBILIZAÇÕES ESTUDANTIS NAS REDES SOCIAIS}

Conforme afirmado inicialmente, a motivação em torno dessa temática, para além das práticas de pesquisa que desenvolvo ${ }^{3}$, deu-se através de uma mobilização surgida no campus da instituição em que atuo como docente. A partir de um contexto nacional de cortes no orçamento das universidades federais, houve uma intensa manifestação contrária às demissões de funcionários do setor terceirizado da instituição. Ao mesmo tempo em que, do ponto de vista da gestão institucional, debates a respeito dos cortes no orçamento eram realizados, com a publicização das medidas a serem tomadas, a organização do coletivo "Bloco de Lutas pela Educação Pública" mobilizou-se e, no dia 12 de maio de 2016, após uma reunião entre a Reitoria e equipes diretivas dos dez campi da universidade 4 na qual não houve possibilidade de reversão nas demissões dos funcionários terceirizados, os estudantes decidiram ocupar o campus. Rapidamente, a página na rede social do "Bloco de Lutas" começou a ser compartilhada, com atualização ao longo dos dias, fotos, agenda das atividades na ocupação, vídeos, entre outros. A utilização da página do grupo na rede social, oportunizou a divulgação das práticas e conectou os sujeitos a partir de uma demanda comum, reforçando-se. Conforme Manuel Castells discute:

Todas as formas de organização social informal que existem na sociedade, que não são organizações políticas tradicionais, mas que são da sociedade, ao estarem conectadas entre elas através da internet, foram um híbrido de redes de diferentes tipos que se reforçam entre elas. (CASTELLS, 2014, p. 172)

A organização da ocupação na Unipampa/Jaguarão ganhou forte repercussão no município. De movimento de um grupo de alunos, passou a ganhar adesão quando as categorias discentes de cada curso do campus realizaram suas assembleias e optaram por paralisação geral das atividades de ensino. Na segunda semana da ocupação, os professores da Educação Básica do

3 Atualmente, coordeno a pesquisa "Cibersocialidade e Inclusão digital no município de Jaguarão: construindo potencialidades educacionais”, que está em fase de conclusão e tem por objetivo analisar o contexto de cibersocialidade e inclusão digital no município de Jaguarão, explorando suas potencialidades educacionais desenvolvidas na Educação Básica.

4 A Universidade Federal do Pampa é uma instituição multicampi, com dez sedes em cidades do pampa gaúcho, essencialmente localizada no sul do Rio Grande do Sul. A Reitoria fica em Bagé e, além desta há campus nos seguintes municípios: Alegrete, Caçapava do Sul, Dom Pedrito, Itaqui, Jaguarão, Santa do Livramento, São Borja, São Gabriel e Uruguaiana. 
estado do Rio Grande do Sul também iniciaram uma greve contra as políticas do governo estadual e contra o parcelamento dos salários, e uma unificação das mobilizações começou a ocorrer em todo o estado e teve grande reflexo na cidade de Jaguarão. No Estado do Rio Grande do Sul, muitas escolas foram ocupadas. A página do Facebook "Ocupa Tudo RS" mantém atualizadas as mobilizações nas escolas estaduais. São mais de dezesseis mil seguidores dessa página.

Atualmente, enquanto escrevo, o campus Jaguarão continua ocupado, da mesma forma como uma escola estadual da Educação Básica em Jaguarão. Mobilizações em conjunto e forte divulgação das organizações e reivindicações na rede social: o município de Jaguarão ganhou visibilidade inclusive na mídia nacional ${ }^{5}$. Reportagens de canais de comunicação e artigos em veículos que discutem a educação brasileira foram apenas alguns exemplos da forma como esse movimento tem sido visibilizado na mídia, através da internet.

Fundamentalmente, o "Bloco de Lutas pela Educação Pública" utiliza a rede social como forma de divulgação das suas ações. Seja no plano da agenda diária (compartilhada por muitos estudantes a partir da página do bloco), seja com fotos e vídeos das atividades realizadas na ocupação, seja para a divulgação das notas públicas emitidas ao longo de suas assembleias. Outro recurso explorado é a transmissão online e síncrona de certas atividades, como plenárias, reuniões com a Reitoria, entre outros. Além disso, a página virtual é espaço de interlocução com outros movimentos estudantis, tanto da própria instituição, quanto de outros grupos organizados no país. Ao reconhecer essa forte organização, assim como a projeção de um movimento local em escala global, interessa problematizar alguns conceitos que são caros a esse entendimento. Um deles diz respeito a sua liderança. Essencialmente, assumem-se como organização coletiva, sem líder, atuando em cooperação para a tomada de decisões. Essa é uma característica importante apontada por Castells em relação aos movimentos sociais na rede:

As redes como tais, em todos os movimentos, não necessitam de uma liderança formal. Por quê? Porque a rede se articula por ela mesma e porque a rede vai mudando conforme vão mudando as circunstâncias em que se desenvolvem os movimentos. Uma estrutura descentralizada desse tipo maximiza as possibilidades de participação. Todo mundo pode entrar na rede, não há barreiras. (CASTELLS, 2014, p. 172)

5 Um dos exemplos é a matéria "UNIPAMPA ocupada - o impressionante movimento no extremo sul do país”. Disponível em: http://www.esquerdadiario.com.br/UNIPAMPA-ocupada-oimpressionante-movimento-no-extremo-sul-do-pais. Acesso em 12 de junho de 2016. 
Com o slogan estampado em sua "foto de capa", trazendo uma imagem que remete a um código de barras e a frase "Educação não é mercadoria", o "Bloco de Lutas pela Educação Pública" tem, atualmente, mais de mil e setecentos seguidores de sua página. Inicialmente, apresentam um manifesto inicial em que apontam alguns fatos que levaram à constituição do grupo, bem como finalizam com seu lema: “Ocupar e resistir, pois só a luta muda a vida!". Essa é a coexistência da demanda local e global:

Uma nova característica: esses movimentos são locais e globais ao mesmo tempo - e isso é algo fundamental. Nascem em situações locais, mas estão em interação constante com o que ocorre em outros lugares do mundo e participam de um debate geral entre as pessoas, em qualquer cultura, que se interessem por uma nova forma de expressão de valores comuns na humanidade. (CASTELLS, 2014, p. 174)

Visitando essa e outras páginas de movimentos estudantis na rede social, requer situar, nas palavras de Castells, a comunicação na sociedade em rede:

O que caracteriza as formas de comunicação de nosso tempo é o fato de elas se basearem em uma comunicação em rede que pode ser operada instantaneamente e pode ser feita a partir de mecanismos que permitam a interação e a comunicação do local ao global e do pessoal ao coletivo em tempo real. (CASTELLS, 2014, p. 170)

A rede possibilita a multiplicidade de conexões em tempo real. Como afirmado anteriormente, o espaço e o tempo se redesenham na sociedade em rede. Assim, para além do movimento que ocorre localmente no campus de uma Universidade, a sua repercussão na rede é impossível de ser mensurada. A cada compartilhamento de uma postagem, a cada "curtida" de uma foto, os limites de visibilidade são expandidos em larga escala. Aí, o ciberespaço atua na construção de uma cibersocialidade: quem curte uma página numa rede social, geralmente, se identifica por um princípio de interesse por aquela temática. E, por conta disso, relações e compartilhamento de ideias podem ser estabelecidas.

Outro aspecto a ser destacado, que rompe com a lógica sobre a relação com os meios de comunicação, é a alteração nas estruturas de divulgação das informações, por conta da conexão instantânea e a possibilidade de compartilhamento rápido entre os sujeitos, em que as estruturas de poder se alteram:

A humanidade está conectada, e por estar conectada é possível estabelecer redes independentes do monopólio que tinham os meios de comunicação de massa e 
independentes das tentativas de controle por parte dos poderes políticos e econômicos. (CASTELLS, 2014, p. 170)

A dinâmica de organização do movimento, expressa em sua página na rede social, e que se consolida em outras ações percebidas na navegação em outros grupos, aponta para uma forma recorrente de atividades: as assembleias e publicação de notas públicas. Oportunizar a todos que expressem a sua palavra é uma marca da cibersocialidade:

Esse sentimento de que todos podem falar, todos podem dizer, é um sentimento de que a horizontalidade da comunicação dentro dessas redes justifica o que muitos movimentos dizem, que as assembleias ou a forma participativa da internet não são um meio, mas um fim. A forma de fazer democracia é a forma de construir democracia. (CASTELLS, 2014, p. 177)

Certamente o reconhecimento do exercício de construção da democracia, ou a reconstrução de princípios democráticos no contexto da sociedade em rede são a expressão emblemática dessa discussão. As mobilizações estudantis nas redes sociais apontam outras visibilidades para a vivência democrática, instauram relações sociais, rompem as fronteiras do "aqui e agora", e ensinam sobre política e educação.

\section{CONSIDERAÇÕES FINAIS}

A proposta de construção deste texto surge da necessidade de se refletir sobre a mobilização estudantil no contexto da sociedade em rede. Um fenômeno complexo que merece atenção, ponderação e criticidade. Sobretudo no campo da educação, de onde me inscrevo, considero-o um fenômeno pedagógico. Porque ensina modos de relação, modos de organização social, modos de se compreender no mundo.

Retomando a ideia do conceito de juventudes, ao analisar as mobilizações estudantis nas redes sociais, implica reconhecer um elemento forte da sua caracterização, o qual aponta a ideia da condição juvenil como condição estudantil. Esse é um elemento que tece a análise pretendida e a perfaz como atrelada ao campo da educação. Ainda, a ideia da cibercultura como a manifestação da singularidade das experiências, reforça o impacto da mobilização que surge no local e se projeta no ciberespaço, reelaborando seus sentidos a partir do compartilhamento das proposições. A rede oportuniza a construção de sentidos e permite que relações horizontais sejam estabelecidas, 
sem que haja preponderância de um sobre outro. Por isso as singularidades emergem, num híbrido de construção das coletividades. Nessa tessitura, a cibersocialidade se demarca, e é meu intuito reforçá-la aqui, como possibilidade de análise daquilo que é vivido no "não institucional". As escolhas, os posicionamentos, as reivindicações se manifestam em distintos espaços, sob a forma de relações construídas a partir das referências ao coletivo, alicerçado sobre uma identidade que não se reforça ou se referenda nas instituições.

Certamente tais mobilizações, bem como suas ações no âmbito local (e presencial) são alvo de críticas e contrariedade. Não cabe incluir uma construção avaliativa a seu respeito, mas quero reiterar a ideia da "juventude como problema", que fortemente se alicerçou na construção da leitura sociológica sobre as juventudes a partir da década de 1960, e se refaz nas mais diversas expressões sociais. Não há unanimidade em relação aos movimentos sociais, tanto na sociedade em rede como fora dela. Muitas vezes, inclusive, a rede potencializa a divergência, naquilo que muitos têm definido como o "discurso de ódio" que impera na evidência dos posicionamentos. E, principalmente quando se fala em concepções juvenis, essas mais uma vez são deslegitimadas por muitos, por conta de um entendimento social de sua inoperância com demandas políticas "sérias".

Romper com tais concepções, reconhecendo a potência das mobilizações estudantis nas redes é um ato que reforça a ideia de pensar aquilo que chamo de "fenômeno pedagógico": a instauração da cibersocialidade, que desdobra uma nova forma de cultura e convivência no cotidiano dos sujeitos, ensina e, sobretudo, ensina sobre democracia: “[...] que estão aprendendo através desse processo é a reconstrução de um processo de decisão coletiva e democrática" (CASTELLS, 2014, p. 176). E a história atual da sociedade brasileira tem nos demonstrado que pensar sobre democracia é o imperativo mais urgente de todos. Que saibamos aprofundar as leituras sobre as mobilizações estudantis nas redes sociais como forma de compreender o nosso tempo, em suas singularidades e, da mesma forma, em suas pluralidades.

\section{REFERÊNCIAS}

ABRAMO, Helena Wendel. Cenas juvenis: punks e darks no espetáculo urbano. São Paulo: Scritta, 1994.

Considerações sobre a tematização da juventude no Brasil. Revista Brasileira de Educação, n.5/6, mai-dez, 1997, p. 25-36. 
CASTELLS, Manuel. A Sociedade em Rede. São Paulo: Paz e Terra, 2007.

A Sociedade em Rede e os movimentos sociais. In: SCHÜLLER, F. L.; WOLF, E. (Org.). Pensar o contemporâneo. Porto Alegre: Arquipélago Editorial, 2014, p. 164-89.

DAYRELL, Juarez. O jovem como sujeito social. Revista Brasileira de Educação, n. 24, set-dez 2003, p.40-52.

ELIAS, Norbert. Sobre o tempo. Rio de Janeiro: Jorge Zahar, 1998.

LEFEBVRE, Henry. O direito à cidade. São Paulo: Centauro, 2001.

LEMOS, André. Cibercultura, tecnologia e vida social na cultura contemporânea. Porto Alegre: Sulina, 2008.

LÉVY, Pierre. Cibercultura. São Paulo: Ed. 34, 2007.

MACHADO, Juliana Brandão. As temporalidades no cotidiano de jovens porto-alegrenses. 2006. 167 f. Dissertação (Mestrado em Educação) Faculdade de Educação, Universidade Federal do Rio Grande do Sul, Porto Alegre. 2006.

As experiências formadoras da docência: estudo das trajetórias formativas de professoras-cursistas do curso PEAD/UFRGS. 2013. $257 \mathrm{f}$. (Doutorado em Educação) - Faculdade de Educação, Universidade Federal do Rio Grande do Sul, Porto Alegre. 2013.

PERALVA, Angelina. O jovem como modelo cultural. Revista Brasileira de Educação, n.5/6, mai-dez, 1997, p. 15-24.

SANTOS, Milton. A natureza do espaço: técnica e tempo, razão e emoção. São Paulo: Editora da Universidade de São Paulo, 2008.

THOMPSON, E. P. O tempo, a disciplina do trabalho e o capitalismo industrial. In: SILVA, Tomaz. T. da (Org.). Trabalho, educação e prática social: por uma teoria da formação humana. Porto Alegre: Artes Médicas, 1991, p. 44-93. 
Cibersocialidad, sociedad en red y educación: sobre movilizaciones estudiantiles en tiempos de redes sociales

Resumen: El objetivo del texto es discutir las prácticas de movilización estudiantil en tiempos de virtualización de las relaciones, a partir de sus manifestaciones en las redes sociales. Para tal discusión fueron señalados los conceptos de sociedad en red, cibersocialidad y juventudes. La motivación inicial parte del contexto de ocupación de un campus universitario por estudiantes, en un escenario de movilización y resistencia que se expande en las redes sociales. El análisis señala que las manifestaciones estudiantiles, vividas en la cibercultura, denotan nuevas prácticas de democracia y, por eso, instituyen un nuevo proceso pedagógico. La reconstrucción de los principios democráticos en el contexto de la sociedad en red es la expresión de tales movilizaciones. Por lo tanto, las movilizaciones estudiantiles en las redes sociales apuntan otros sentidos para la vivencia democrática, instauran relaciones sociales, rompen las fronteras del "aquí y ahora", y enseñan sobre política y educación.

Palabras-clave: Educación. Redes Sociales. Cibersocialidad. Movilización Estudiantil. Sociedad en Red. 
Cybersociality, network society and education: on student mobilizations in times of social networks

\begin{abstract}
The purpose of the text is to discuss the practices of student mobilizations in times of virtualization of relationships, based on their manifestations in the social networks. For such discussion, we summarized the concepts of network society, cybersociality and youths. The initial motivation arises from the context of occupation of a university campus by students, in a scenario of mobilization and resistance which expands in social networks. The analysis points out that student manifestations, experienced in cyberculture, denote new practices of democracy and, consequently, institute a new pedagogic process. The reconstruction of democratic principles in the context of a network society is the expression of such mobilizations. Therefore, student mobilizations in social networks point out other meanings for the democratic living, establish social relationships, break down the boundaries of "here and now", and teach about politics and education.
\end{abstract}

Keywords: Education. Social Networks. Cybersociality. Student Mobilization. Network society. 
Cibersocialidade, sociedade em rede e educação 